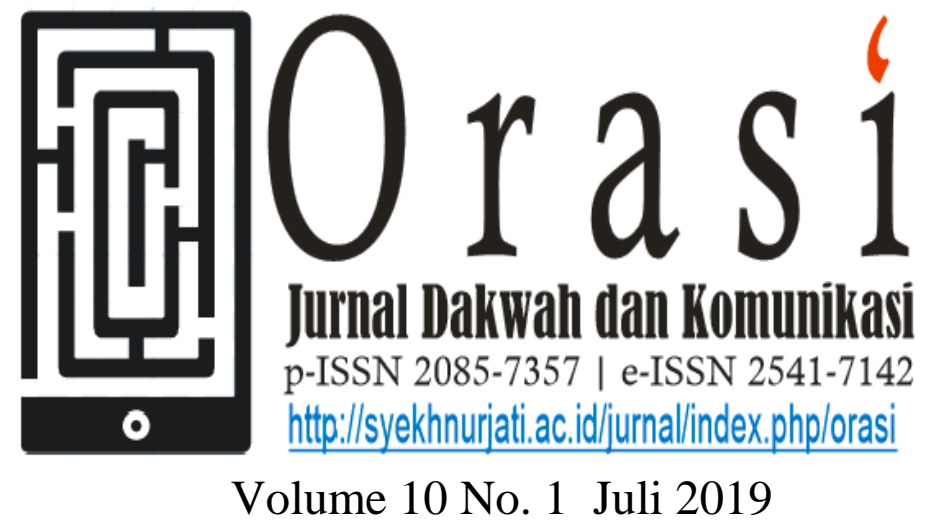

\title{
MINAT MAHASISWA KOMUNIKASI PENYIARAN ISLAM (KPI) FAKULTAS USULUDDIN ADAB DAN DAKWAH IAIN SYEKH NURJATI CIREBON MENJADI JURNALIS
}

(Studi Kasus Pada Mahasiswa KPI 2015-2016)

\author{
Mia Melindasari1,a), Arief Rachman',b) \\ 1,2 Jurusan Komunikasi dan Penyiaran Islam, IAIN Syekh Nurjati Cirebon \\ Jl. Perjuangan By Pass Sunyaragi Cirebon \\ e-mail: ${ }^{a}$ melindaasuhandi@gmail.com, , b) arief.rachman@ syekhnurjati.ac.id
}

\begin{abstract}
Journalists are those who carry out journalistic practice activities, including events that report and write through the mass media. A journalist must have a trustworthy and honest personality. Students, as human beings who are exploring the world of lectures, have become commonplace if they have some expertise that is mastered, one of which is writing or making news especially journalistic students related to writing and making news has become daily food. As a forum for honing creativity, some KPI Study Program students actively participate in print and electronic media such as tabloids, newsletters, radio and television.

The problem of this research is how students' interest in the Faculty of Ushuluddin Adab KPI and IAIN Da'wah Sheikh Nurjati Cirebon became journalists. What are the factors supporting the students of the Faculty of Ushuluddin Adab KPI and the IAIN Da'wah of Nurjati Cirebon becoming journalists. What are the inhibiting factors for the students of the Faculty of Ushuluddin Adab KPI and IAIN Da'wah Sheikh Nurjati Cirebon being journalists.

The purpose of this study was to find out the student interest of the Faculty of Ushuluddin Adab KPI and IAIN Syekh Nurjati Cirebon became a journalist, what factors supporting the students of the Faculty of Ushuluddin Adab and IAIN Da'wah of Nurjati Cirebon became journalists, and to find out what the KPI
\end{abstract}


students were Faculty of Islamic Education Adab and IAIN Da'wah Sheikh Nurjati Cirebon became a journalist.

This research was conducted using a case study approach. This type of research uses qualitative research that does not carry out statistical calculations in carrying out the analysis. Data collection techniques used are interviews, documentation studies, and observations. The data analysis method used is descriptive analysis method where the results of the study are presented in a qualitative descriptive manner. The data analysis steps are as follows: Data reduction, data presentation, and conclusion drawing.

The results of the study showed that most of the interest in the Faculty of Shuluddin Adab KPI students and SyekhNurjati IAIN Da'wah in Cirebon were to become journalists when viewed from the reasons for choosing the KPI department interested in journalism. Factors supporting the students of the Faculty of Shuluddin Adab KPI and Shaykh Nurjati IAIN Da'wah in Cirebon became a journal for a large part because of their hobbies of writing and job opportunities in industrial media which were quite large. unable to utilize information technology and inadequate infrastructure.

Keywords: Journalists, Electronic Media, Student Interest, Information Technology.

\begin{abstract}
ABSTRAK
Jurnalis adalah seorang yang melakukan kegiatan praktik jurnalistik, meliputi peristiwa kegiatan melaporkan dan menuliskan melalui media massa. Seorang jurnalis haruslah memiliki kepribadian yang amanah dan jujur. Mahasiswa, sebagai manusia yang sedang menjajaki dunia perkuliahan sudah menjadi hal biasa jika memiliki beberapa keahlian yang di kuasai, salah satunya adalah menulis atau membuat berita khususnya mahasiswa jurnalistik terkait dengan menulis dan membuat berita sudah menjadi makanan sehari-hari. Sebagai wadah mengasah kreatifitas, beberapa mahasiswa Prodi KPI ikut aktif dalam media cetak dan media elektronik seperti, tabloid, buletin, radio dan telivisi.

Masalah penelitian ini adalah bagaimana minat mahasiswa KPI Fakultas Ushuluddin Adab dan Dakwah IAIN Syekh Nurjati Cirebon menjadi jurnalis. Apa faktor-faktor pendukung mahasiswa KPI Fakultas Ushuluddin Adab dan Dakwah IAIN Syekh Nurjati Cirebon menjadi jurnalis.Apa faktor-faktor penghambat mahasiswa KPI Fakultas Ushuluddin Adab dan Dakwah IAIN Syekh Nurjati Cirebon menjadi jurnalis.

Tujuan penelitian ini adalah untuk mengetahui minat mahasiswa KPI Fakultas Ushuluddin Adab dan Dakwah IAIN Syekh Nurjati Cirebon menjadi jurnalis, apa faktor-faktor pendukung mahasiswa KPI Fakultas Ushuluddin Adab dan Dakwah IAIN Syekh Nurjati Cirebon menjadi jurnalis, dan untuk mengatahui apa faktorfaktor penghambat mahasiswa KPI Fakultas Ushuluddin Adab dan Dakwah IAIN Syekh Nurjati Cirebon menjadi jurnalis.

Penelitian ini dilakukan menggunakan pendekatan studi kasus. Jenis pnelitian ini menggunakan penelitian kualitatif yang tidak mengadakan perhitungan statistik dalam melaksanakan analisa. Teknik pengumpulan data yang digunakan yaitu wawancara, studi dokumentasi, dan observasi. Metode analisis data yang digunakan yaitu metode analisis deskriptif dimana hasil penelitian disajikan
\end{abstract}


secara kualitatif deskriptif.Dengan langkah-langkah analisis data sebagai berikut : Reduksi data, penyajian data, dan penarikan kesimpulan.

Hasil penelitian menunjukkan bahwa sebagian besar minatmahasiswa KPI FakultasUshuluddinAdab dan Dakwah IAIN SyekhNurjati Cirebonadalah ingin menjadi jurnalis jika dilihat dari alasan memilih jurusan KPI tertarik dengan jurnalistik. Faktor pendukung mahasiswa KPI FakultasUshuluddinAdab dan Dakwah IAIN SyekhNurjati Cirebonmenjadijurnalissebagian besar dilatar belakangi karena hobi menulis dan peluang kerja di media industri yang cukup besar.Faktor Penghambat Mahasiswa KPI Fakultas Ushuluddin Adab dan Dakwah IAIN Syekh Nurjati Cirebon menjadi jurnalis, yaitu cara dosen mengajar yang monoton, mahasiswa kurang bisa memanfaatkan teknologi informasi serta sarana prasarana yang kurang memadai.

Kata Kunci: Jurnalis, Media elektronik, Minat Mahasiswa, Teknologi Informasi.

\section{Pendahuluan}

Minat dalam kamus bahasa Indonesia adalah kegemaran, kecenderungan, kesukaan (Ananda, 2005: 236).Minat adalah suatu pemusatan perhatian yang tidak disengaja yang terlahir dengan penuh kemauannya dan yang tergantung dari bakat dan lingkungannya (Agus, 2012: 92).

Menurut Crow J dan Crow K dalam (Djaali, 2011:121) mengatakan bahwa minat berhubungan dengan gaya gerak yang mendorong seseorang untuk menghadapi dan berurusan dengan orang, benda, kegiatan, pengalaman yang dirangsang oleh kegiatan itu sendiri. Menurut Slameto (2010:180) suatu minat dapat diekspresikan melalui suatu pernyataan yang menunjukan bahwa siswa lebih menyukai suatu hal daripada hal lainnya, dapat pula dimanifestasikan melalui partisipasi dalam suatu aktivitas. Siswa yang memiliki minat terhadap subyek tertentu cenderung untuk memberikan perhatihan yang lebih besar terhadap subjek tersebut.

Bakat merupakan suatu potensi atau kemampuan khusus dan lebih dominan yang dimiliki seseorang, yang dapat berkembang melalui proses pelatihan dan pendidikan intensif. Dengan proses ini, bakat akan menjadi sebuah kemampuan dan kecakapan nyata. Mengembangkan bakat dan minat bertujuan agar seseorang bisa bekerja di bidang yang diminatinya dan sesuai dengan kemampuan serta bakat dan minat yang dimilikinya sehingga mereka bisa mengembangkan kapabilitas untuk bekerja secara optimal dengan penuh antusias. (www.bakat.pdf.com.2012).

Berdasarkan uraian di atas minat yang dimaksud dalam penulis ini adalah dorongan atau keinginan dalam diri seseorang pada objek tertentu, minat bukanlah sesuatu yang statis atau berhenti, tetapi dinamis. Batasan minat yang di maksud penulis adalah keinginan mahasiswa KPI Fakultas Ushuluddin Adab dan Dakwah IAIN Syekh Nurjati Cirebon untuk menjadi seorang jurnalis. Karena seiring perkembangan zaman banyak sekali bermunculan media massa, hal ini tentu menjadi peluang mahasiswa KPI untuk memilihkarir di bidang tersebut.

Pesatnya kemajuan media informasi dewasa ini cukup memberikan kemajuan yang signifikan. Media cetak maupun elektronik pun saling bersaing kecepatan sehingga pemburu berita dituntut kreativitasnya dalam penyampaian informasi. Penguasaan dasar-dasar pengetahuan jurnalis merupakan modal yang amat penting manakala kita terjun di dunia ini. Keberadaan media tidak lagi sebatas penyampai informasi 
yang aktual kepada masyarakat, tapi media juga mempunyai tanggung jawab yang berat dalam menampilkan fakta untuk selalu bertindak objektif dalam setiap pemberitaannya. (www.pelitaku.sabda.2010).

Perkataan journal, artinya catatan harian, atau catatan mengenai kejadian sehari-hari, atau bisa juga berarti surat kabar. Journal berasal dari perkataan latin diurnalis, artinya harian atau tiap hari. Dari perkataan itulah lahir kata juranalis, yaitu orang yang melakukan pekerjaan jurnalis (Budyatna, 2006: 15).Jurnalis atau journalisme berasal dari perkataan journal, artinya catatan harian, atau catatan mengenai kejadian sehari-hari, atau bisa juga berarti surat kabar. Journal berasal dari perkataan latin diurnalis, artinya harian atau tiap hari. Dari perkataan itulah lahir kata juranalis, yaitu orang yang melakukan pekerjaan Jurnalis (Budyatna, 2006: 17).

Secara etimologis, Jurnalis berasal dari kata journ. Dalam bahasa perancis, journ berarti catatan atau laporan harian. Secara sederhana Jurnalis diartikan sebagai kegiatan yang berhubungan dengan pencatatan atau pelaporan setiap hari. Dalam kamus, Jurnalis diartikan sebagai kegiatan untuk menyiapkan, mengedit dan menulis untuk surat kabar, majalah dan perkara lainnya. Menurut Ensiklopedi Indonesia, Jurnalis adalah bidang profesi yang mengusahakan penyajian informasi tentang kejadian atau kehidupan sehari-hari (pada hakekatnya dalam bentuk penerangan, penafsiran, dan pengkajian) secara berkala, dengan menggunakan sasaran-sasaran penerbit yang ada (Sumadiria, 2011: 2).

Sementara ada juga yang mendefinisikan jurnalis yaitu seni dan / ketrampilan mencari, mengumpulkan, mengolah, menyusun, dan menyajikan berita tentang peristiwa yang terjadi sehari-hari secara indah, dalam rangka memenuhi segala kebutuhan hati nurani khalayaknya (Kostadi,
2004: 23). Indah dalam hal ini yaitu dapat dinikmati sehingga bisa mengubah sikap, sifat, pendapat, tingkah laku khalayak.

Jurnalis adalah seorang yang melakukan kegiatan praktik Jurnalis, meliputi peristiwa dan menuliskan atau melaporkanya melalui media masa. Seorang jurnalis haruslah memiliki kepribadian yang amanah dan jujur dalam menulis berita yang ditulisya. Disamping itu juga seorang jurnalis memiliki ketelitian dan keakuratan informasi yang didapat. Seorang jurnalis, jika tidak mengetahui suatu kejadian atau suatu masalah secara pasti, dan membutuhkan sumber berita, harus selektif dalam mengklasifikasi sumber berita dan memverifikasi kebenaran berita tersebut.

Mahasiswa, sebagai manusia yang sedang menjajaki dunia perkuliahan sudah menjadi hal biasa jika memiliki beberapa keahlian yang di kuasai, salah satunya adalah menulis atau membuat berita khususnya mahasiswa Jurnalistik (Komunikasi dan Penyiaran Islam) terkait dengan menulis dan membuat berita sudah menjadi makanan sehari-hari. Namun untuk orang yang bukan dari jurusanJurnalis mungkin membuat berita tidak semudah yang orang pikirkan dan katakan. Tetapi, saat ini dengan munculnya Jurnalisme warga atau Citizen Journalism sudah cukup membuktikan bahwa untuk menulis atau membuat berita tidak hanya bisa dilakukan mahasiswa dari Jurnalistik atau Wartawan professional saja, namun warga pun bisa menjadi atau terlibat dalam proses pembuatan berita dengan meliput atau menulis kejadian yang terjadi di lingkungannya, yang memang berita tersebut layak untuk diwartakan kepada masyarakat luas.

Dari uraian di atas, dapat dipahami bahwa seorang jurnalis harus memiliki integritas yang tinggi. Sehingga informasi yang dipublikasikan dapat dipertanggung jawabkan dan memiliki kebermanfaatan bagi 
masyarakat. Keberadaan mahasiswa jurusan KPI pada Fakultas Ushuluddin Adab dan Dakwah IAIN Syekh Nurjati Cirebon sangat relevan dengan keinginan untuk mewujudkan kerja jurnalis yang jujur, teliti, dan dapat dipertanggung jawabkan.

Di jurusan KPI ini mahasiswa sudah dibekali dengan mata kuliah keahlian sebagai bahan dasar untuk menunjang minat yang ada di dalam diri mahasiswa tersebut agar tidak rasa memilih minat menjadi jurnalis, secara strukturr kurikulum, porsi mata kuliah yang membekali mahasiswa untuk menjadi seorang jurnlis sebenarnya sangat memadai, apalagi porsi mata kuliah yang menyiapkan untuk menjadi seroang jurnalis yang memiliki integritas yang tinggi.

Namun demikian, dari sekian banyak mahasiswa jurusan KPI, masih mahasiswa yang berminat untuk terjun di bidang jurnalis. Sekarang ini khusunya mahasiswa di Fakultas Ushuluddin Adab dan Dakwah IAIN Syekh Nurjati Cirebon yang berminat terjun di media cetak. Mahasiswa KPI lebih tertarik bergabung di media-media elektronik seperti Radio dan Telivisi. Seperti diketahui dari hasil wawancara mahasiswaKPI yang telah bergabung di beberapa radio,hal itu membuktikan bahwa mereka benar-benar berminat di bidang jurnalis. Mereka menerapkan apa yang telah mereka pelajari di bangku kuliah, hal ini berdampak positip bagi mahasiswa tersebut dan Fakultas juga turut berbangga dengan mereka. ${ }^{1}$

Dalam mata kuliah Jurnalistik yang diberiakan pada mahasiswa jurusan Komunikasi dan penyiaran Islam (KPI) Fakultas Usuluddin Adab dan DakwahIAIN Cirebon mendukung mahasiswa untuk bergerak di bidang komunikasi dan industri media yaitu sebagai jurnalis, baik sebagai

\footnotetext{
${ }^{1}$ Hasil Wawancara Mahasiswa KPI
} FUAD IAIN Syekh Nurjati Cirebon, Cirebon, 3 Januari 2018 jurnalis profesional.Maupun hanya berkecimpung di dunia tulisan baik dalam seperti media bulletin pondok, buletin kampus, hal inilah yang menjadi penulis untuk melakukan penelitian.

Sebagian mahasiswa, selain aktif di Radio, ada juga mahasiswa yang sudah bergabung di stasiun telivisi lokal seperti TV Radar, di sana mahasiswa membawakan suatu acara talk show. Hal Ini tentunya menjadi kebanggaan tersendiri bagi FakultasUsuluddin Adab dan Dakwah. Karena mereka bisa dikatakan berhasil menerapkan apa yang telah dipelajari di bangku perkuliahan. Berdasarkan latar belakang di atas penulis tertarik mengambil penelitian yang berjudul: "Minat Mahasiswa Komunikasi dan Penyiaran Islam (KPI) Fakultas Usuluddin Adab Dan Dakwah IAIN Syekh Nurjati Cirebon Menjadi Jurnalis (Studi Kasus Pada Mahasiswa KPI 20152016)".

\section{Metode Penelitian}

\subsection{Rumusan Masalah}

Berdasarkan latar belakang diatas dapat dibuat rumusan masalah sebagai berikut:

a. Bagaimana minat mahasiswa KPI Fakultas Ushuluddin Adab dan Dakwah IAIN Syekh Nurjati Cirebon menjadi jurnalis?

b. Apa faktor-faktor pendukung mahasiswa KPI Fakultas Ushuluddin Adab dan Dakwah IAIN Syekh Nurjati Cirebon menjadi jurnalis?

c. Apa faktor-faktor penghambat mahasiswa KPI Fakultas Ushuluddin Adab dan Dakwah IAIN Syekh Nurjati Cirebon menjadi jurnalis?

\subsection{Tujuan Penelitian}

Adapun tujuan dari penelitian ini adalah sebagai berikut: 
a. Untuk mengetahui bagaimana minat mahasiswa KPI Fakultas Ushuluddin Adab dan Dakwah IAIN Syekh Nurjati Cirebon menjadi jurnalis

b. Untuk mengetahui apa sajafaktor-faktor pendukung mahasiswa KPI Fakultas Ushuluddin Adab dan Dakwah IAIN Syekh Nurjati Cirebon menjadi jurnalis

c. Untuk mengatahui apa saja faktorfaktorpenghambat mahasiswa KPI Fakultas Ushuluddin Adab dan Dakwah IAIN Syekh Nurjati Cirebon menjadi jurnalis

\subsection{Jenis Penelitian}

Penelitian ini menggunakan penelitian kualitatif yang tidak mengadakan perhitungan statistik dalam melaksanakan analisa, peneliti bergerak di antara tiga komponenya itu reduksi data, penyajian data, dan penarikan kesimpulan.

Lebih jelas metode penelitian ini didasarkan pada metode penelitian deskriptif. Dengan penelitian deskriptif kita tidak hanya puas bila hanya mengetahuiapa masalahnya, tetapi ingin mengetahui juga bagaimana peristiwa tersebuat terjadi.

\subsection{Pendekatan Penelitian}

Penelitian ini menggunakan
pendekatan studi kasus. Studi kasus
merupakan suatu metode penelitian dalam
ilmu sosial yang hasilnya akan diperoleh
pemahaman yang mendalam tentang
mengapa sesuatu terjadi dan dapat menjadi
dasar bagi riset selanjutnya.

\section{Hasil dan Pembahasan}

\subsection{Komunikasi Massa}

Menurut Bittner komunikasi massa adalah pesan yang dikomunikasikan melalui media massa pada sejumblah besar orang. Dari definisi tersebut dapat diketahui bahwa komunikasi massa itu menggunakan media massa (Ardianto, 2012:3).

Menurut Severin dan Tankard, Jr. komunikasi itu adalah keterampilan, seni, dan ilmu, dikaitkan dengan pendapat Devito bahwa komunikasi massa itu ditunjukan kepada massa dengan melalui media massa di bandingkan dengan jenis-jenis komunikasi lainnya (Effendy, 2013: 21).

\subsubsection{Konsep komunikasi massa}

Salah satu perubahan teknologi baru itu menyebabkan dipertanyakannya kembali definisi komunikasi itu sendiri. Komunikasi massa bias didefinisikan dalam 3 ciri yaitu (Severin\& James, 2011:4):

a. Komunikasi massa diarahkan kepada audiens yang relative besar, heterogen, dan anonim.

b. Pesan-pesan yang disebarkan secara umum, sering dijadwalkan untuk bias mencapai sebanyak mungkin anggota audiens secara serempak dan sifatnya sementara.

c. Komunikator cenderung berada atau beroperasi dalam sebuah organisasi yang kompleks yang mungkin membutuhkan biaya yang besar.

\subsubsection{Fungsi komunikasi massa}

Fungsi komunikasi massa menurut Domininick terbagi menjadi 5 yaitu (Ardianto, 2012:14-17):

a. Pengawasan

b. Penafsiran

c. Penyebaran Nilai-nilai

d. Entertainment (Hiburan)

\subsubsection{Karakteristik Komunikasi Massa}

a. Komunikator terlembaga

b. Pesan bersifat umum

c. Komunikannya anonim dan heterogen.

d. Media massa menimbulkan keserampakan

e. Komunikasi mengutamakan isi ketimbang hubungan.

f. Komukasi massa bersifat satu arah

g. Stimulasi alat indra terbatas

h. Umpan balik tertunda (Deleyed) dan tidak langsung (Indirect)

Komponen umpan balik atau yang lebih populer dengan sebutan feedback 
merupakan faktor paling penting dalam proses komunikasi antarpesona, komunikasi kelompok, dan komunikasi massa. Efektivitas komunikasi seringkali dapat dilihat dari feedblack yang disampaikan oleh komunikan.

\subsection{Jurnalistik}

\subsubsection{Pengertian Jurnalistik}

Istilah jurnalis dari kata jurnalistik yang berarti dari bahasa prancis "journal", berarti catatan harian. Jurnalistik berkaitan dengan kata catatan harian yang dipublikasikan kepada masyarakat dan terbit secara tertentu. Jurnal atau the jour berarti hari, dimana segala berita atau warta seharihari itu termuat dalam sebuah lembaran yang tercetak. Dalam perkembangan istilah jurnalistik disenadakan dengan pers atau jurnalis.

Adapun pengertian jurnalistik menurut pendapat Romli dalam buku Jurnalistik Praktis, mengemukakan:

Jurnalistik dapat dipahami sebagai proses kegiatan meliput, membuat dan menyebarluaskan peristiwa yang bernilai berita (news) dan pandangan (views) kepada khalayak melalui saluran media massa baik cetak maupun elektronik. Sedangkan pelakunya disebut jurnalis atau jurnalis (2001:70).

Dari berbagai literatur, dapat dikaji bahwa definisi jurnalistik adalah suatu pengolahan laporan harian yang menarik minat khalayak mulai dari peliputan sampai penyebaran kepada masyarakat melalui media massa baik cetak maupun elektronik.

Kegiatan jurnalistik memilik prinsip-psrinsip hal ini juga dijelaskan dalam karya Sudirman Tebba, Jurnalistik Baru, yakni :
a. Tidak boleh memasukkan opini pribadi.
b. Berita yang disajikan hanya fakta yang mengandung kebenaran.
c. Unsure $5 \mathrm{~W}+1 \mathrm{H}$ tetap ada.

d. Penulisan berita harus tepat, ringkas, jelas, sederhana dan dapat dipercaya.

e. Naskah berita harus lugas dan mengandung daya gerak (2005: 3)

Proses jurnalistik adalah setiap kegiatan mencari, mengumpulkan, menyeleksi, dan mengolah informasi yang mengandung nialai berita, serta menyajikan pada khalayak melalui media massa periodik, baik cetak maupun elektronik.

Amar yang dikutip Sumadiria (2005:30) dalam bukunya Jurnalistik Indonesia, mengatakan bahwa:

Jurnalistik adalah kegiatan mengumpulkan, mengeolah, dan menyebarkan berita kepada khalayak seluas-luasnya dengan secepatcepatnya. Setiap bentuk jurnalistik memiliki ciri dan kekhasannya masingmasing. Ciri dan kekhasannya itu antara lain terletak pada aspek filosofi penerbitan, dinamika teknis persiapan dan pengelolaan, serta asumsi dampak yang ditimbulkan terhadap khalayak pembaca, pendengar atau pemirsa.

Suhandang (2004:21) dalam bunya Pengantar jurnalistik, Seputar Organisasi, dan Kode Etik memberikan pengertian jurnalistik sebagai berikut:

Jurnalistik dalah seni dan keterampilan mencari, mengumpulkan, mengolah menyusun, dan menyajikan berita tentang peristiwa yang terjadi sehari hari secara indah, dalam rangka memenuhi segala kebutuhan hati nurani khalayaknya, sehingga terjadi perubahan sikap, sifat, pendapat, dan perilaku khalayak sesuai dengan para jurnalisnya.

\subsubsection{Bentuk Jurnalistik}

Jurnalistik dibagi ke dalam tiga bagian besar dilihat dari segi bentuk dan pengelolaannya menurut Sumadiria (2005: 5) dalam bukunya Jurnalistik Indonesia adalah sebagai berikut: 
a. Jurnalistik Media Cetak (newspaper and magazine journalism).

Media baru merupakan istilah yang dipakai untuk semua bentuk media komunikasi massa yang berbasis teknologi komunikasi dan teknologi informasi. Media baru yang memiliki cirri tersebut adalah internet. Internet adalah jaringan kabel dan telpon satelit yang menghubungkan computer (Vivian, 2008: 263).Ciri media baru internet menurut Dennis McQuail (2011:150) pertama internet tidak hanya berkaitan dengan produksi dan distribusi pesan tetapi juga dapat disetarakan dengan pengolahan, pertukaran dan penyimpanan. Kedua, media baru merupakan lembaga komunikasi publik dan privat, dan diatur (atau tidak) dengan layak. Ketiga, mereka tidak seteratur sebagaimana media massa yang professional dan birokratis.

b. Jurnalistik Media Elektronik Auditif (radio broadcast journalism).

Media ini lebih banyak dipengaruhi oleh dimensi verbal, teknologikal dan fisikal. Verbal berhubungan dengan kemampuan menyusun kata, kalimat dan paragraf secara efektif dan komunikatif. Teknologikal berkaitan dengan teknologikal yang memungkinkan daya pancar radio dapat ditangkap dengan jelas dan jernih oleh pesawat radio penerima. Sedangkan fisikal, erat kaitannya dengan tingkat kesehatan fisik dan kemampuan pendengaran khalayak dalam menyerap dan mencerna setiap pesan kata atau kalimat yang disampaikan.

c. Jurnalistik Media Elektronik Audio visual (television journalism).

Merupakan gabungan dari segi verbal, visual, teknologikal dan dimensi dramatikal.

\subsubsection{Kompetensi Menjadi Jurnalis}

Kompetensi yang dibutuhkan oleh seorang jurnlis adalah sebagai berikut: a. Pengetahuan (Knowledge)

Jurnalis dituntut untuk menguasai sejumlah pengetahuan dasar seperti ilmu pengetahuan umum (budaya, sosial, politik) dan pengetahuan khusus, serta pengetahuan teknis. Jurnalis perlu mengetahui perkembangan ,mutakhir ilmu pengetahuan sebagai basis informasi untuk memerankan fungsi pers sebagai pendidik dan informatif. Jurnalis tanpa pengetahuan yang memadai, hanya akan menghasilkan karya jurnalistik yang berisi informasi yang dangkal dan tidak memberikan pencerahan bagi masyarakat.

b. Keterampilan (Skill)

Penguasaan keterampilan adalah mutlak bagi jurnalis, mustahil mampu menjalankan tugas sebagai jurnalis jika seseorang tidak meguasai teknik jurnalistik, seperti teknik menulis, atau teknik wawancara. Selain itu, jurnalis harus menguasai perangkat keras yang dibutuhkan untuk membantu ketika bekerja seperti computer, faksimile, scanner dan lain-lain.

c. Profesionalisme Jurnalis

Jurnalis harus bersikap profesional, karena pers memiliki kekuatan untuk mempengaruhi publik melalui informasi, dan jurnalis memiliki "hak istimewa" dalam menjalankan profesinya, seperti hak mendapatkan akses informasi / data dan hak tolak.

\subsection{Minat}

\subsubsection{Pengertian Minat}

Minat adalah sesuatu pemusatan perhatian yang tidak disengaja yang terlahir dengan penuh kemauannya dan yang tergantung dari bakat dan lingkungannya (Agus Sujanto, 2012: 92).

Menyatakan (Jogiyanto 2007; 28) Minat adalah kecenderungan jiwa yang tetap untuk memperhatikan dan mengenang beberapa aktivitas atau kegiatan. Jadi apabila seseorang berminat untuk memperhatikan suatu aktivitas dan melakukan aktivitas yang dilakukan pasti dengan dilandasi rasa senang 
dalam melakukannya. Jika menimbulkan rasa senang, maka seseorang di masa yang akan datang akan secara terus - menerus ingin menggunakannya.

\subsubsection{Unsur-Unsur Minat}

Seseorang dikatakan berminat terhadap sesuatu bila individu itu memiliki beberapa unsur antara lain sebagai berikut:

a. Perhatian

Seseorang dikatakan berminat apabila individu disertainya adanya perhatian, yaitu kreativitas jiwa yang tinggi yang semata-mata tertuju pada suatu obyek, jadi seseorang yang berminat terhadap sesuatu obyek yang pasti perhatiannya akan memusat terhadap sesuatu tersebut.

\section{b. Kesenangan}

Perasaan senang terhadap suatu obyek baik orang ataupun benda akan menimbulkan minat pada diri seseorang, orang yang merasa tertarik kemudian pada gilirannya timbul keinginan yang dikehendaki agar obyek tersebut menjadi miliknya.

c. Kemauan

Kemauan yang dimaksud adalah dorongan yang terarah pada suatu tujuan yang dikehendaki oleh akal pikiran. Dorongan ini akan melahirkan timbulnya suatu perhatian terhadap suatu obyek. Sehingga dengan demikian akan muncul minat individu yang bersangkutan.

Dari uraian diatas, dapat dijelaskan bahwa jika seseorang perhatian kepada suatu obyek dengan rasa senang dan ia berkemauan yang tinggi untuk memiliki ataupun mendapatkannya seperti minat menjadi seorang jurnalis, jika ia bersungguh-sungguh mau belajar dan berusaha maka minat atau pun keinginannya tersebut bisa tercapai.

\subsubsection{Ciri-Ciri Minat}

Dari pemahaman beberapa pendapat yang telah dikemukakan diatas maka ciri-ciri minat sebagai berikut:

a. Adanya rasa senang dan keterkaitan terhadap objek yang diminati.

b. Adanya rasa butuh terhadap apa yang diminati.

c. Ulet menghadapi suatu kesulitan.

\subsubsection{Implementasi Minat}

Implementasi atau Penerapan

jurnalis berpendapat bahwa cara yang paling efektif untuk membangkitkan minat pada suatu sobjek yang baru adalah dengan menggunakan minat-minat mahasiswa yang telah ada. Para pengajar berusaha untuk membentuk minat-minat baru pada mahasiswa.

Hal ini bisa di capai melalui jalan memberi informasi pada mahasiswa tentang bahan yang akan disampaikan dengan menghubungkan materi yang lalu kemudian dipraktekkan secara langsung. Hal ini bisa dicapai dengan cara menghubungkan bahanbahan berita yang sensasional agar mudah di pahami dan diketahui oleh mahasiswa. Untuk menumbuhkan minat terhadap suatu kegiatan seperti jurnalis, usahakan memperoleh keterangan untuk bagaimana menumbuhkan suatu minat agar dapat melakukan kegiatan tersebut secara efektif.

\subsection{Mahasiswa}

\subsubsection{Pengertian Mahasiswa}

Mahasiswa adalah seseorang yang sedang dalam proses menimba ilmu ataupun belajar dan terdaftar sedang menjalani pendidikan pada salah satu bentuk perguruan tinggi yang terdiri dari akademik, politeknik, sekolah tinggi, institut dan universitas (Hartaji, 2012: 5).

Dalam Kamus Bahasa Indonesia (KBI), mahasiswa didefinisikan sebagai orang yang belajar di Perguruan Tinggi (Kamus Bahasa Indonesia Online, kbbi.web.id) 
Menurut Siswoyo (2007: 121) mahasiswa dapat didefinisikan sebagai individu yang sedang menuntut ilmu ditingkat perguruan tinggi, baik negeri maupun swasta atau lembaga lain yang setingkat dengan perguruan tinggi. Mahasiswa dinilai memiliki tingkat intelektualitas yang tinggi, kecerdasan dalam berpikir dan kerencanaan dalam bertindak. Berpikir kritis dan bertindak dengan cepat dan tepat merupakan sifat yang cenderung melekat pada diri setiap mahasiswa, yang merupakan prinsip yang saling melengkapi.

\subsubsection{Karakteristik}

Perkembangan

Mahasiswa

Seperti halnya transisi dari sekolah dasar menuju sekolah menengah pertama yang melibatkan perubahan dan kemungkinan stres, begitu pula masa transisi dari sekolah menengah atas menuju universitas. Dalam banyak hal, terdapat perubahan yang sama dalam dua transisi itu. Transisi ini melibatkan gerakan menuju satu struktur sekolah yang lebih besar dan tidak bersifat pribadi, seperti interaksi dengan kelompok sebaya dari daerah yang lebih beragam dan peningkatan perhatian pada prestasi dan penilaiannya (Santrock, 2002: 74)

\section{Simpulan}

1) Minat mahasiswa KPI di Fakultas Ushuluddin Adab dan Dakwah IAIN Syekh Nurjati Cirebon menjadi jurnalis berdasarkan hasil penelitian yaitu sebenarnya berasal dari kesadaran diri sendiri, dan keinginan menjadi seorang jurnalis yang handal,selain itu pun mereka tertarik dengan mata kuliah jurnalistik.

2) Faktor pendukung mahasiswa KPI Fakultas Ushuluddin Adab dan Dakwah IAIN Syekh Nurjati Cirebon menjadi jurnalis berdasarkan hasil penelitian yaitu sebagian besar dilatar belakangi karena hobi menulis dan kerja lapangan yang cukup menjanjikan.

3) Faktor penghambat mahasiswa KPI Fakultas Ushuluddin Adab dan Dakwah IAIN Syekh Nurjati Cirebon menjadi jurnalis berdasarkan hasil penelitian yaitu cara dosen mengajar yang monoton, mahasiswa kurang bisa memanfaatkan teknologi informasi, sertasarana prasaranayang kurang memadai.

\section{Daftar Pustaka}

Buku:

Amir, Mafri. (2003). Etika Komunikasi dalam Pandangan Islam.Jakarta: Logos.

Ananda Santoso \& S. Ptiyanto. (1995). Kamus Lengkap Bahasa Indonesia, Surabaya: Kartika.

Ardianto, Elvinaro. et al. (2012). Komunikasi Massa Suatu Pengantar Edisi

Revisi. Bandung: Simbiosa Rekatama Media.

Arikunto, S. (2006). Prosedur Penelitian, Jakarta: PT Rineka Cipta. (2010) Prosedur Penelitian, Suatu Pendekatan Praktek, Jakarta: Rineka Cipta.

As. Haris. Sumadiria, (2005). Jurnalistik Indonesia, Menulis Berita dan Feature, Panduan Praktis Jurnalis Profesional. Bandung: PT. Remaja Rosdakarya.

Assegaf, Djafar H. (2001). Jurnalistik Media Kini. Jakarta: Ghalia Indonesia.

Budyatna, Muhammad. (2006). Jurnalistik Teori \& Praktek, Bandung: PT Remaja Rosdakarya.

Cangara, Hafied. (2013). Perencanaan dan Strategi Komunikasi, Jakarta: Rajawali Pers.

Dewi Astari, Esti. (2010). Minat Menjadi Jurnalis Pada Mahasiswa Komunikasi Dan Penyiaran Islam 
Fakultas Dakwah Dan Ilmu

Komunikasi Iain Raden Intan

Lampung. Lampung: Fakultas

Dakwah dan Ilmu Komunikasi IAIN

Raden Intan Lampung.

Djafar Assegaf. (2001). Jurnalistik Massa

Kini, Jakarta: Ghalia Indonesia.

Dokumentasi dengan Kasubag Akademik \& Kemahasiswaan, FUAD IAIN Syekh Nurjati Cirebon, data mahasiswa KPI, Cirebon, 6 Januari 2017

Effendi Siregar, Amir. (2003) Pers Mahasiswa Indonesia, Jakarta: Karya Unipress.

Effendy, Onong Uchjana. (2013). Ilmu, Teori dan Filsafat Komunikasi. Bandung: PT. Citra Aditya Bakti.

Fauji Hadiono, Abdi. (2017). Jurnalistik dan Minat Mahasisiwa (Studi Pengaruh Mata Kuliah Jurnalistik Terhadap Minat Mahasiswa KPI IAIDA Blokagung Banyuwangi Menjadi Jurnalis), Banyuwangi: Fakultas Fakultas Dakwah dan Ilmu Komunikasi IAIDA Blokagung Banyuwangi.

Hadi, Sutrini, Methodologi Research Jilid III, Yogyakarta: Fakultas Psikologi UGM, 1 th.

Hafidhuddin, Didin. (2000). Dakwah Aktual, Jakarta: Gema Insani Press.

Hermawan, Asep. (2005). Penelitian Bisnis Paradigma Kuantitatif, Jakarta: PT Grasindo.

Junaedhie Kurniawan. (1991). Ensiklopedi Pers Indonesia, Jakarta: Gramedia Pustaka Utama.

Kartono, Kartini. (2000). Metode Penelitian Masyarakat, Jakarta: Bina Karya.

Kriyantono, Rachmat. (2009). Teknik Praktis Riset Komunikasi. Jakarta: Kencana.

Lexy J. Moleong. (2007). Metodologi Penelitian Kualitatif, Bandung: Remaja Rosdakarya.
M. Romli, Asep Syamsul. (2001). Jurnalistik Terapan, Bandung: Batic Press.

Maman Abdul Djajel. (1997). Prinsip Dan Strategi Dakwah, Jakarta: Prenada Media.

Mc Quail, Denis. (2011). Teori Komunikasi Massa. Jakarta: Salemba Humanika.

Observasi, Mahasiswa KPI FUAD IAIN Syekh Nurjati Cirebon, Cirebon, 3 Januari 2018

Poerwadarminta, W.J.S. (2005). Kamus Umum Bahasa Indonesia. Edisi Ketiga. Jakarta: Balai Pustaka

Roberston, Roland, Agama dan Analisis Sosial dalam Thomas W. Arnold, Sejarah Agama-Agama tt: t.p. t.th

Romli, Asep Samsul. (1999). Jurnalistik Praktis Untuk Pemula, Jakarta: Grasindo.

Sanit, Arbi. (2009). Pergolakan Melawan Kekuasaan, Gerakan Mahasiswa Antara Aksi Moral dan Politik. Dalam Skripsi Abdul Rohman.

Santoso, Ananda \& S. Ptiyanto. (2005). Kamus Lengkap Bahasa Indonesia, Surabaya: Kartika.

Severin, Werner J dan James W Tankard. (2011). Teori Komunikasi: sejarah, Metode, Terapan di Dalam Media Massa, Jakarta: Kencana.

Septiawan Santana K. (2005). Jurnalisme Kontemporer. Jakarta: Yayasan Obor Indonesia.

Sudijono, Anas. (2009). Pengantar Statistik Pendidikan. Jakarta: Rajawali pers.

Sudjana, Nana. (2006). Pedoman Penyusun Skripsi, Tesis Desertasi, Jakarta: Reneka Cipta.

Sugiyono. (2010). Metode Penelitian Pendidikan: Pendekatan Kuantitatif, Kualitatif, dan $R \& D$, Bandung: Alfabeta.

Suhandang, Kustadi. (2004). Pengantar Jurnalistik (Seputar Organisasi, 
Produk dan Kode Etik, Bandung:

Nuansa Cendikia.

Sujanto, Agus. (2012). Psikologi Umum, Jakarta: PT Bumi Aksara.

Sumadiria, AS Haris. (2011). Jurnalistik Indonesia, Bandung: Simbiosa Rakatama Media.

Sutrisno, Hadi. (2004). Metodologi Research. Yogyakara: Andi Offset.

Tebba, Sudirman. (2005). Jurnalistik Baru. Cipitat: Kalam Indonesia.

Toha Jahja Oeman. (1971). Ilmu Dakwah, Jakarta: Wijaya.

Wahyudi. J. W. (1991). Komunikasi Jurnalistik (Pengetahuan Praktis Bidang Kewartawanan, SuratkabarMajalah, Radio dan Televisi), Bandung: Alumni.

Winkel W.S. (1986). Psikologi Pendidikan dan Evaluasi Belajar. Jakarta: PT. Gramedia.

\section{Internet:}

Elisa Fitri, Faktor Minat, (On-Line), tersedia di:

http://www.belajarbagus.com/2015/ 04/minat-belajar.html (15 Mei 2018).

http://iainukebumen.ac.id/2014/08/masadepan-karir-di-bidang-komunikasidan-penyiaran-islam/ diakses 2 Maret 2018

http://romeltea.com/prospek-karier-jurusankomunikasi-penyiaran-islam-kpi/ diakses, 2 Maret 2018

Khusairi, "Definisi Minat" (On-Line), tersedia di: http://uinkediri.blogspot.co.ia/2014/ 12/makalah-definisi-minatbelajar.html (29 Mei 2018).

Tina. Mina., (On-Line), tersedia di: http://adityaromantika.blogspot.co.i d/2010/12minat.html (10 Mei 2018) 